\title{
Fungi over fungi, endophytic fungi associated with mushroom fruiting bodies and lichens
}

\author{
Waill A. Elkhateeb ${ }^{1}$ and Ghoson M. Daba ${ }^{1}$ \\ ${ }^{1}$ Chemistry of Natural and Microbial Products Department, Pharmaceutical Industries Division, National Research Centre, Dokki, Giza, \\ 12622, Egypt.
}

Corresponding Author: Waill A. Elkhateeb, Department of Pharmaceutical Industries Division, National Research Centre, Dokki, Giza, 12622, Egypt.

Received date: January 09, 2021; Accepted date: January 20, 2021; Published date: February 17, 2021

Citation: Waill A. Elkhateeb, Ghoson M. Daba (2021) Fungi over fungi, endophytic fungi associated with mushroom fruiting bodies and lichens $J$. Pharmaceutics and Pharmacology Research 4(2); DOI: 10.31579/2693-7247/028

Copyright: ( ) 2021, Waill A. Elkhateeb, This is an open access article distributed under the Creative Commons Attribution License, which permits unrestricted use, distribution, and reproduction in any medium, provided the original work is properly cited.

\begin{abstract}
Mushrooms are macrofungi that are famous for their nutritional and pharmaceutical values. On the other hand, lichens are the form of symbiosis representing the complex relation between fungi and algae. Understanding the ability of fungi to grow over anything, this review is focusing on endophytic fungi capable of growing in association with mushrooms and lichens, respectively. Although reports describing these association are rare, it is important to highlight such relation, and encourage for conducting more studies in order to understand the consequences of growth of endophytes on mushroom, status of lichen endophytes, and to investigate the diversity of endophytic fungi within lichen thalli.
\end{abstract}

Keywords: endophytic fungi; mushrooms; lichens; endolichenic; biological activities

\section{Introduction}

Fungal endophytes constitute a major part of the unexplored fungal diversity. Endophytic fungi are an important source for novel, potential and active metabolites. Bioactive compounds produced by endophytes main function are helping the host plants to resist external biotic and abiotic stress, which benefit the host survival in return. These organisms mainly consist of members of the Ascomycota, Basidiomycota, Zygomycota and Oomycota. Endophytes are productive ground for drug discovery. Endophytic fungi are considered as the hidden members of the microbial world and represent an underutilized resource for new therapeutics and compounds. Endophytes are rich source of natural products displaying broad spectrum of biological activities like anticancer, antibacterial, antiviral, immunomodulatory, antidiabetic, antioxidant, anti-arthritis and anti-inflammatory [1-4].

Discovery and development of new antibiotics is still very important because of the continuous appearance of drug-resistant pathogenic bacteria, endophytes play that role and also endophytes play important role in the growth and development of the host $[5,6]$. They can participate in the metabolic processes of the host, produce biological macromolecules with growth-promoting or antibacterial activities, and affect the yield and quality of the host [7, 8]. However, the study of endophytes is mostly focused on plants and animals, and reports on endophytic flora are moderately rare [9-11]. Many large mushrooms have a complex life history and demanding environmental requirements. Studying the community structure of organisms in mushrooms may be significant for their cultivation.

\section{Endophytic fungi associated with mushrooms}

Fruit-body production of mushrooms is not well understood to date as many factors interact with mushroom growth in nature. Weather conditions play a key role, but they do not completely explain the growth and productivity of wild mushrooms. Mycorrhizal fungi depend on photosynthetically fixed carbon produced by their associated trees, and the physiological state of host trees may well drive the growth of these fungi. We raise the question of whether mycorrhizal fungi can be used as indicators for tree health [12]. The study of endophytes is mostly focused on plants and animals, and reports on microorganisms associated with fungus are relatively rare [13]. The soil surrounding mushrooms mycelia contains varied microbial communities that may affect the growth of mushrooms mycelium and the formation of fruiting body [14].

Tricholoma matsutake fruiting bodies are rare and commercially valuable. Polysaccharides and terpenoids extracted from the fruiting body have anti-tumor and antioxidant properties [15-18]. Li et al., [13], studied the endophytic microorganisms associated with twelve samples of Tricholoma matsutake fruiting bodies in three locations in Sichuan, China, and reported that Tricholoma matsutake fruiting bodies have 13 fungus, 15 yeast and 14 bacterial strains. The most abundant cultivable fungus, yeast and bacteria isolates were assigned as Fusarium solani, Cryptococcus sp. and Pseudomonas sp., respectively. Beta and gammaproteobacteria, Acidobacteria, Bacteroidetes and Sphingobacterium were found in samples from all collecting sites. Among these bacteria, we may find some strains that can promote the growth of Tricholoma matsutake $[19,20]$.

\section{Mushrooms on mushrooms}

On other hand mushrooms can grow on mushrooms but not as endophytic fungi but as parasitic fungi. Asterophora species this mushrooms 
belonging to Basidiomycetes, family: Lyophyllaceae can grows as a parasite on other mushrooms in complete form [21]. This fascinating mushroom is a parasite on other mushrooms like Russula densifolia. It pops right out of the top of its victim, usually when the Russula has blackened and begun to decay. Also there are other mushrooms that parasitize russulas and are superficially similar, including species of Collybia and another species of Asterophora, Asterophora parasitica. Among these parasites, Asterophora lycoperdoides is unique in having a cap surface that soon becomes covered with brown powder [21]. Asterophora parasitica (basidiomycete) is a mushroom that grows on mushrooms. Hypomyces lactifluorum (ascomycete) is a parasite of fleshy mushrooms (basidiomycetes). The parasitized mushrooms are edible and are sold as "lobster mushrooms". This is one of the strangest mushrooms on Earth, it were a gilled mushrooms that parasitizes other mushrooms, which already makes it a rarity [21], (Figure, 1).

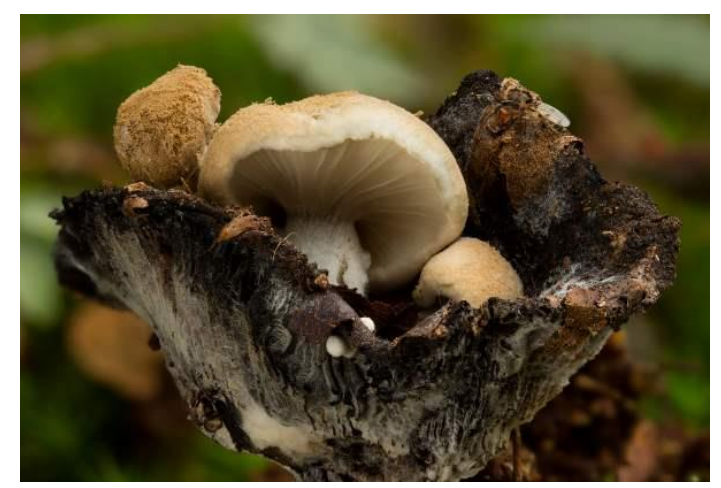

Figure (1). Asterophora different species.

(Cited in: https//www.forestfloornarrative.comblog20191115the-fungal-parasite-asterophora-lycoperdoides and https//www.firstnature.comfungiasterophora-lycoperdoide).

\section{Endophytic fungi associated with lichens}

Microbial endophytes have been found in the leaves, bark and xylem of higher plants [22-24], including grasses [25], also in lower forms like algae [26], and mosses [27]. Lichen thalli provide a mostly unexplored and uncharted ecological niche for a wide variety of microorganisms including fungi. Endolichenic fungi have an intimate association and live in the thalli of lichens that are similar to plant endophytic fungi [22]. Endolichenic fungi also reported as parasymbionts in lichens [28]. A number of fungi grow and produce fruiting bodies on the surface of lichen thalli with identical fructifications. The terms lichenicolous or endolichenic fungi are different because of their occurrence or association on surface or within tissues of internal parts [29]. Some researchers used the term endolichenic because they isolated from internal tissues [30], and others isolated endolichenic fungal strains that lived along in the lichen thallus Pseudocephaelaria sp. Usnea sp. and Parmotrema species. Lichens are economically important as traditional medicine and food in some regions [31-33]. Endolichenic fungal strains isolated from lichen thalli Pseudocyphellaria sp., Parmotrema sp. and Usnea sp. also showed biological activities as antifungal activities against common plant pathogenic fungi [34].

A recovery of endolichenic fungi from tissue segments of lichen thalli showed that these fungi not found on surface sterilized lichen thalli [35]. The colonization of fungi was considered environmental contaminants. Fungi belong to soil and litter symbiosis or pathogenic also isolated from fruticose lichens which were symbionts or pathogens of higher plants and lichens inhabiting fungi [28]. Although there are several studies on endophytic microorganisms of higher plants, but very few studies were carried out on the isolation of endolichenic fungi from the lichen thallus $[30,36,37]$.

Vinayaka et al., [29], reported that about 300 genera and 1000 species of obligatory lichenicolous fungi known which form parasitic, saprophytic, parasymbiotic and obligatory symbiotic mode of biological relationships on lichen species. Vinayaka et al., [29], have examined some lichen species for isolation of endolichenic fungi from the internal tissues of macrolichens which commonly occur in forests of Bhadra Wildlife Sanctuary, Southern India. A total of 30 different endolichenic fungal species were recovered from 11 species of foliose and fruticose lichens. Twenty four species of isolated fungi have produced fructifications. Among the 30 isolates, 24 species were identified in that most of them were belonging to ascomycota. The fungal species associated with thalli of lichen species were Chaetomium globosum, Cladosporium cladosporoides, Colletotrichum dematium, Fusarium heterosporum, Phoma sp. and Xylaria species. A total of 389 strains of fungi belonging to 38 species were isolated from 10 lichen species of the Western Ghats, southern India. All the lichens screened, irrespective of their growth forms or location, harboured endolichenic fungi. Most of the fungi belonged to the Ascomycotina. Chaetomium sp., Hypoxylon investiens, Nemania bipapillata, Nodulisporium sp., Paecilomyces sp., and Sporormiella intermedia were the most common ones and were present in 5 or more lichen species. Of the 28 sporulating fungi, 7 belonged to Xylariales, and their total colonization frequency in all the lichens was also high [38].

Association of endolichenic fungi with eleven lichen species belongs to five families distributed in Bhadra Wildlife Sanctuary, South India were investigated during May, 2013 to January, 2014. A total of 30 endolichenic taxa from 486 segments were isolated. Chaetomium globosum was occurred in eight, among 11 species of lichen, it was the dominant species of endolichenic fungi in thalli of lichens screened. The Ramalina pacifica and Parmotrema tinctorum showed maximum colonization by the endolichenic fungi. Out of 30 species of fungi 24 were sporulated and they were identified up to genus/species level. Chaetomium globosum, Fusarium spp., Xylaria sp. were isolated from thalli of lichen species [29]. Li et al., [31], reported that endophytic fungi of seven lichen species belonging to five families were investigated in Baihua mountain of Beijing. Various endophytic fungi were found among the lichens. A total of 32 taxa from 488 thallus segments were obtained, with 14 ascomycetes, 16 hyphomycetes, one ceolomycetes and one yeast. Scopulariopsis sp. was distributed in six out of seven lichens and was the dominant species in five lichens. Geniculosporium serpens was the dominant species in the lichen, Dermatocarpon miniatum. Sporormiella species only occurred in Xanthoria mandschurica. This review represent 
that abundant endophytic fungi are distributed within different lichen thalli and the endophytic fungi is different among the lichens.

\section{Conclusion}

The study of microorganisms in mushrooms fruiting body is still comparatively rare, and many information need to answered many questions. The growth-promoting activity of associated organisms should be tested, and their role in material exchange between mushrooms host and endophytic fungi should be evaluated. On the other hand, endolichenic fungi are interesting type of lichens-fungal interactions. As the lichens composed of symbiosis relationship, these non-obligatory endolichenic fungal presence in lichen thalli attracts further study regarding lichen-fungi inter-relationship and their significance in symbiosis, parasitism. Many studies must be conducted in order to understand the status of lichen endophytes, and to investigate the diversity of endophytic fungi within lichen thalli.

\section{References}

1. Rajamanikyam M, Vadlapudi V, Upadhyayula SM. (2017). Endophytic fungi as novel resources of natural therapeutics. Brazilian Arch Biol and Technol., 60: 1-26.

2. Elkhateeb WA. Ghoson MD. (2018). Where to Find? A Report for Some Terrestrial Fungal Isolates, and Selected Applications Using Fungal Secondary Metabolites. Biomed J Sci Technol Res., 4(4): 14.

3. Daba GM, Elkhateeb WA, Paul W. Thomas (2018). This era of biotechnological tools: an insight into endophytic mycobiota. Egyptian Pharmaceu J, 17(3): 121-128.

4. El-Kassem LA, Hawas UW, El-Souda S, Ahmed EF, El-Khateeb W, Fayad W. (2019). Anti-HCV protease potential of endophytic fungi and cytotoxic activity. Biocatalysis and Agricultural Biotechnol. 101170.

5. Dudnik A, Bigler L, Dudler R. (2014). Production of proteasome inhibitor syringolin A by the endophyte Rhizobium sp. strain AP16, Appl. Environ. Microbiol. 80: 3741-3748.

6. Truyens S, Jambon I, Croes S, Janssen J, Weyens N, Mench M, Carleer R, Cuypers A, Vangronsveld J. (2014). The effect of longterm $\mathrm{Cd}$ and $\mathrm{Ni}$ exposure on seed endophytes of Agrostis capillaris and their potential application in phytoremediation of metalcontaminated soils, Int. J. Phytoremediat., 16: 643-659.

7. Alvin A, Miller KI, Neilan BA. (2014). Exploring the potential of endophytes from medicinal plants as sources of antimycobacterial compounds, Microbiol. Res., 169: 483-495.

8. Aschehoug ET, Callaway RM, Newcombe G, Tharayil N, Chen SY. (2014). Fungal endophyte increases the allelopathic effects of an invasive forb. Oecologia, 175: 285-191.

9. Feng NX, Yu J, Zhao HM, Cheng YT, Mo CH, Cai QY, Wong MH. (2017). Efficient phytoremediation of organic contaminants in soils using plant-endophyte partnerships. Sci Total Enviro., 583: 352368.

10. Prasad M, Srinivasan R, Chaudhary M, Mahawer SK, Jat LK. (2020). Endophytic bacteria: Role in sustainable agriculture. In Microbial Endophytes (pp. 37-60). Woodhead Publishing.

11. Rai M, Rathod D, Agarkar G, Dar M, Brestic M, Pastore GM, Junior MR. (2014). Fungal growth promotor endophytes: a pragmatic approach towards sustainable food and agriculture. Symbiosis, 62(2): 63-79.

12. Egli S. (2011). Mycorrhizal mushroom diversity and productivityan indicator of forest health? Ann Forest Sci., 68(1): 81-88.

13. Li Q, Chen C, Penttinen P, Xiong C, Zheng L, Huang W. (2016). Microbial diversity associated with Tricholoma matsutake fruiting bodies. Microbiol. 85(5): 531-539.

14. Kataoka R, Siddiqui ZA, Kikuchi J, Ando M, Sriwati R, Nozaki A, Futai K. (2012). Detecting nonculturable bacteria in the active mycorrhizal zone of the pine mushroom Tricholoma matsutake. $J$ Microbiol, 50(2): 199-206.

15. Hou Y, Ding X, Hou W, Zhong J, Zhu H, Ma B, Li J. (2013). Antimicroorganism, anti-tumor, and immune activities of a novel polysaccharide isolated from Tricholoma matsutake. Pharmacognosy magazine, 9(35): 244.

16. Tong H, Liu X, Tian D, Sun X. (2013). Purification, chemical characterization and radical scavenging activities of alkali-extracted polysaccharide fractions isolated from the fruit bodies of Tricholoma matsutake. World J Microbiol Biotechnol., 29(5): 775780.

17. You LJ, Gao Q, Feng MY, Yang B, Ren JY, Gu LJ, Cui C, Zhao MM. (2013). Structural characterisation of polysaccharides from Tricholoma matsutake and their antioxidant and antitumour activities, Food Chem., 138: 2242-2249.

18. You QH, Yin XL, Zhang SN, Jiang ZH. (2014). Extraction, purification, and antioxidant activities of polysaccharides from Tricholoma mongolicum Imai, Carbohyd. Polym. 99: 1-10.

19. Oh SY, Kim M, Eimes JA, Lim YW. (2018). Effect of fruiting body bacteria on the growth of Tricholoma matsutake and its related molds. PLoS One, 13(2): e0190948.

20. Oh SY, Park MS, Lim YW. (2019). The Influence of Microfungi on the Mycelial Growth of Ectomycorrhizal Fungus Tricholoma matsutake. Microorganisms, 7(6): 169.

21. Phillips, Roger (2010). Mushrooms and Other Fungi of North America. Buffalo, NY: Firefly Books. pp. 92-93.

22. Arnold AE, Lutzoni F. (2007). Diversity and host range of foliar fungal endophytes: are tropical leaves biodiversity hotspots. Ecol., 88: 541- 549 .

23. Murali TS, Suryanarayanan TS, Venkatesan G. (2007). Fungal endophyte communities in two tropical forests of southern India: diversity and host affiliation, Mycol Progress, 6: 191- 199.

24. Krishnamurthy YL, Naik SB, Shashikala J. (2008). Fungal communities in herbaceous medicinal plants from the Malnad region, Southern India. Microbes and Environ, 23: 24-28.

25. Krishnamurthy YL, Hemalatha TV. (2003). Isolation of Endophytic fungi from some grasses. J Mycol Plant Pathol, 33: 305-306.

26. Hawksworth DL. (1988). The variety of fungal-algal symbioses, their evolutionary significance and the nature of lichens. Botonical J. Linnean Society, 96: 3-20.

27. Dreyfuss MM. (1986). Neue Erkenntnisse aus einem pharmakologischen Pilzscreening. Sydowia, 39: 22-36.

28. Petrini O, Hake U, Dreyfuss MM. (1990). An analysis of fungal communities isolated from fruticose lichens. Mycologia, 82: 444451.

29. Vinayaka KS, Krishnamurthy YL, Banakar S, Kekuda TP. (2016). Association and variation of endophytic fungi among some macrolichens in central Western Ghats, Southern India. Int. J. Curr. Microbiol. Appl. Sci, 5: 115-124.

30. Suryanarayanan TS, Thirunavukkarasu N, Hariharan GN, Balaji P. (2005). Occurrence of non-obligate inside lichen thalli. Sydowia, 57: 120-130.

31. Li WC, Zhou J, Guo SY, Guo LD. (2007). Endophytic fungi associated with lichens in Baihua mountain of Beijing, China. Fungal Divers, 25: 69-80.

32. Elkhateeb WA, Daba GM. (2020). Lichens- masters of extraordinary symbiosis with potent pharmaceuticals. Egyptian Pharmaceu J., 19(3), 197.

33. Elkhateeb WA, Daba G, Sheir D, The-Duy Nguyen, Hapuarachchi K, Thomas P. (2020). Mysterious World of Lichens: Highlights on Their History, Applications, and Pharmaceutical Potentials. The Natural Products J., 10: 1-13.

34. Kannangara BT, Rajapaksha RS, Paranagama PA. (2009). Nature and bioactivities of endolichenic fungi in Pseudocyphellaria sp., 
Parmotrema sp. and Usnea sp. at Hakgala montane forest in Sri Lanka. Lett Appl Microbiol., 48: 203-209.

35. Arnold AE, Jolanta M, Lindsay KH, Snehal DS, Paul G, Amanda W, Valerie H, Frank K, Lutzoni F. (2009). A phylogenetic estimation of trophic transition networks for ascomycetous fungi: Are lichens cradles of symbiotrophic fungal diversification? Systematic Biol., 58: 283-297.

36. Wen-Chao L, Zhou J, Shou YG, Guo LD. (2007). Endophytic fungi associated with lichens in Baihua mountain of Beijing, China. Fungal Diversity, 25: 69-80.

37. Harutyunyan S, Muggia L, Grube M. (2008). Black fungi in lichens from seasonally arid habitats. Studies in Mycol., 61: 83-90.

38. Rajulu MB, Thirunavukkarasu N, Kumar S, Kaur T, Reddy M, Suryanarayanan TS. (2020). Endolichenic fungal diversity associated with some lichens of the Western Ghats. Planta medica, 86(13/14): 960-966. 